\title{
BMJ Open Sex disparities in premature adult mortality in Estonia 1995-2016: a national register-based study
}

\author{
Kaja Rahu, ${ }^{\oplus 1}$ Mati Rahu, ${ }^{1}$ Hajo Zeeb ${ }^{2,3}$
}

To cite: Rahu K, Rahu M, Zeeb H. Sex disparities in premature adult mortality in Estonia 1995-2016: a national register-based study. BMJ Open 2019;9:e026210. doi:10.1136/ bmjopen-2018-026210

- Prepublication history and additional material for this paper are available online. To view these files, please visit the journal online (http://dx.doi. org/10.1136/bmjopen-2018026210).

Received 22 August 2018 Revised 29 May 2019 Accepted 10 June 2019
Check for updates

(c) Author(s) (or their employer(s)) 2019. Re-use permitted under CC BY-NC. No commercial re-use. See rights and permissions. Published by BMJ.

${ }^{1}$ Department of Epidemiology and Biostatistics, National

Institute for Health Development, Tallinn, Estonia

${ }^{2}$ Department of Prevention and Evaluation, Leibniz Institute for Prevention Research and Epidemiology, Bremen, Germany ${ }^{3}$ Health Sciences Bremen, University of Bremen, Bremen, Germany

Correspondence to

Dr Kaja Rahu; kaja.rahu@tai.ee

\begin{abstract}
Objectives To quantify sex disparities in cause-specific premature adult mortality in Estonia, to determine the causes of death with the largest differences, to provide insight into related behaviours and to offer some guidance to public health policy-makers based on the results of the study.

Design A national register-based study.

Setting Estonia.
\end{abstract}

Data Individual records of deaths at ages 20-69 years in 1995-2016 from the Estonian causes of death register; data on tobacco smoking and alcohol consumption in the adult population in 1996-2016 from the biennial postal survey of health behaviour.

Main outcome measures Overall and cause-specific age-standardised mortality rates, average annual percentage changes in mortality, and cause-specific mento-women mortality rate ratios were calculated. In addition, the age-standardised prevalence proportions of tobacco smoking and alcohol consumption and men-to-women prevalence rate ratios were determined.

Results Overall premature adult mortality decreased considerably during 1995-2016, but no reduction was observed with respect to the large relative sex disparities. In circulatory disease mortality, the disparities widened significantly over time. Extremely high mortality rate ratios were observed for cancer of the upper aerodigestive tract and for lung cancer. There was a stable, more than fivefold male excess mortality from external causes. A fourfold male disadvantage was evident for alcohol poisoning, mental disorders due to alcohol and alcoholrelated degeneration of the nervous system as a group. The prevalence of tobacco smoking and harmful alcohol consumption among men exceeded that among women by factors of two and six, respectively.

Conclusions Even though premature adult mortality has markedly decreased over time, there has been no success in diminishing the large sex differences in the mortality patterns, mostly associated with smoking and excessive alcohol consumption, both more prevalent among men. Estonia needs a comprehensive and consistent alcohol policy while maintaining and further developing antitobacco measures.

\section{INTRODUCTION}

Estonia is a high-income country in northern Europe with an area of $45230 \mathrm{~km}^{2}$ and a population of 1.3 million. According to data

\section{Strengths and limitations of this study}

This study is the first to report sex disparities in cause-specific premature adult mortality in Estonia with an emphasis on alcohol-related and smoking-related causes of death.

- Special attention paid to cause-specific men-towomen mortality rate ratios helped to reveal different health behaviour among men and women.

- Individual death records from the population-based mortality register were used.

- The exclusion of deaths records with an unknown date of birth (more common among men) slightly reduced the men-to-women mortality rate ratios.

- Heavy alcohol consumption has likely been underestimated in the Estonian health behaviour survey.

from 2017, the country's gross domestic product per capita (2011 PPP \$) was 29481 (40th globally). Estonia belongs to the group of countries with a very high human development index (30th globally) and a very high gender inequality index (27th globally). ${ }^{1}$ Among the 28 European Union member countries (EU-28), Estonia ranks third with the largest sex gap in life expectancy at birth. ${ }^{2}$ Over the decade of 1976-1985, life expectancy at birth in Soviet Estonia remained almost unchanged, fluctuating between 64 and 65 years for men and between 74 and 75 years for women (figure 1$).^{3}$ Gorbachev's antialcohol campaign, launched in $1985,{ }^{4}$ triggered a remarkable short-term improvement in male life expectancy-from 64.6 in 1985 to 66.6 in 1988 . The positive trend was followed by a sharp decrease during the dissolution of the Soviet Union and the first years of Estonian reindependence in 1991-1994 because of worsening of macroeconomic conditions and related fall in living standards, which coincided with weakening of alcohol restrictions. ${ }^{5}$ Life expectancy for men and women dropped to the lowest level in 1994, 60.5 and 72.8 years, respectively. From 1995 onwards, life expectancy has increased markedly, reaching 73.2 years for men and 


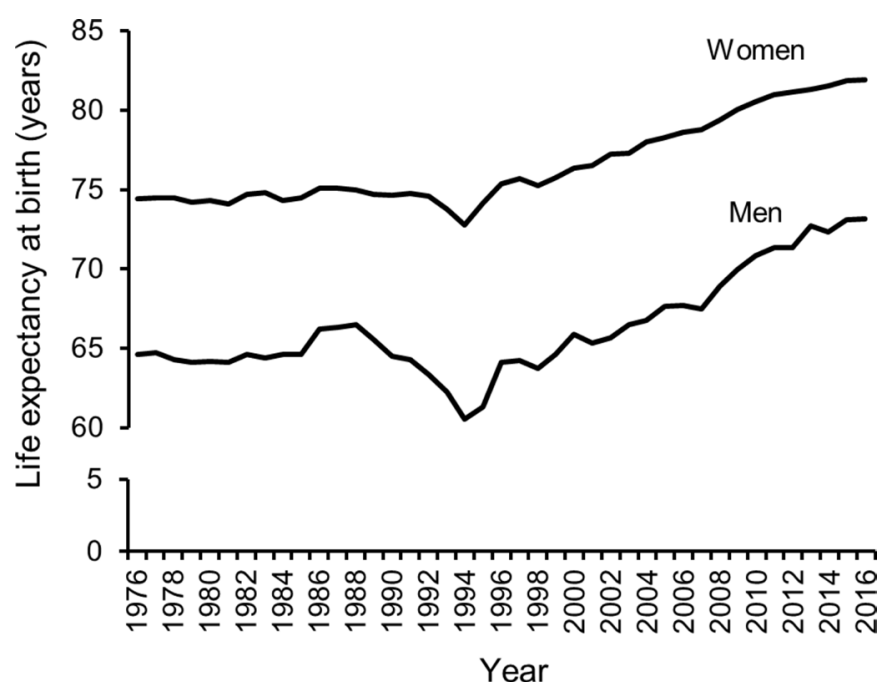

Figure 1 Life expectancy at birth, Estonia, 1976-2016. ${ }^{3}$

81.9 years for women in $2016^{3}$ (compared with the EU-28 average of 78.2 and 83.6 , respectively ${ }^{6}$ ); however, the male disadvantage of 9-10 years has remained unchanged. The lowest difference of 8.4 years was observed in 1988, but in 2016, the difference still stands at 8.7 years. Although women outlive men all over the world, ${ }^{7}$ only $1-2$ years of the sex gap can be explained by biological factors. ${ }^{8}$

The objective of the present study was to quantify relative sex disparities in cause-specific premature adult mortality in Estonia over time. We wanted to determine for which causes of death the inequalities were the largest, providing insight into related behaviours that differ the most between Estonian men and women. Finally, we aimed to offer some guidance to public health policy-makers based on the results of the study.

\section{METHODS}

\section{Data}

Individual death data in 1995-2016 were obtained from the Estonian causes of death register including single records since $1983 .{ }^{9}$ Premature adult deaths were defined as those occurring between the ages of 20 and 69 years, setting the upper limit close to the life expectancy for men. We have chosen 1995 as the start year for three reasons: (1) A steady decline in mortality started in this year $^{10}$; (2) A year earlier, a less detailed Soviet classification was replaced with the genuine international classification of diseases (ICD) ${ }^{11} 12$ for coding causes of death (ICD-9 in 1994-1996 and ICD-10 in 1997-2016) ${ }^{13}$ and (3) The victims of the Estonia ferry accident in $1994^{14}$ (120 men and 137 women aged 20-69 years) were thus left out from the analysis. Only underlying causes of death were considered.

In addition, data on smoking and drinking habits in the population aged 20-64 years were obtained from the biennial postal survey of health behaviour of Estonian adult population (the Finbalt survey). ${ }^{15}$

\section{Measures and statistical analyses}

For mortality comparisons, we first calculated the overall and cause-specific age-standardised mortality rates (ASMR; European standard population ${ }^{16}$ ) for the years 1995-2016 for men and women aged 20-69 years. Time trends are presented for overall mortality and for major groups of causes of death: infectious diseases, neoplasms, circulatory diseases, respiratory diseases, digestive diseases and external causes of death. To reduce short-term fluctuations in mortality rates by year, 3-year moving, overlapping periods were used. In addition, time trends for mortality from lung cancer, chronic obstructive pulmonary disease (COPD), cancer of the upper aerodigestive tract (UADT), liver cirrhosis and from a group of mental disorders due to alcohol, alcohol-related degeneration of the nervous system and alcohol poisoning (hereafter AP) are shown. Mortality from these causes is highly sensitive to changes in the prevalence of tobacco smoking and/or alcohol consumption in the population. ${ }^{17-21} \mathrm{AP}$ grouping was performed because of systematic misclassification of these causes in the mortality register, ${ }^{9}$ and the effect of which should be captured by treating these individual causes together. Average annual percentage changes (AAPC) with 95\% confidence intervals (CI) for ASMRs in 1995-2016 were modelled with Poisson regression. For selected alcohol-related causes, the study period was split into two subperiods both including 2007 when alcohol consumption in the country was at its maximum. ${ }^{22}$

Second, Poisson regression was used to estimate cause-specific men-to-women mortality rate ratios (MRRs) with 95\% CI for the period 1995-2016 and the age range of 20-69. The models were adjusted for age (5-year age groups) and year of death. For selected causes of death, MRRs were also calculated separately for the younger (20-44 years) and older (45-69 years) age groups. Poisson regression models were fitted to the annual MRRs to obtain AAPCs.

Third, age-standardised prevalence proportions (ASPP; European standard population) in 1996-2016 for men and women were calculated for daily smoking, heavy episodic drinking ( $\geq 60 \mathrm{~g}$ of pure alcohol per occasion at least once a week) and hazardous drinking $(\geq 210 \mathrm{~g}$ and $\geq 140 \mathrm{~g}$ of pure alcohol weekly for men and women, respectively). Heavy episodic drinking and hazardous drinking were defined as recommended by the Organization for Economic Co-operation and Development. ${ }^{23}$ Men-to-women prevalence proportion ratios (PPRs) with 95\% CIs were calculated using Poisson regression models adjusted for age (5-year age groups) and survey year.

FoxPro 9.0 (Microsoft Corporation, Redmond, WA, USA) was used for database management and Stata 14 (StataCorp LP, College Station, TX, USA) for statistical modelling.

\section{Patient and public involvement}

Patients or public were not involved in this study. 


\section{RESULTS}

In the period 1995-2016, 191123 deaths were registered among men and 189390 deaths among women in Estonia. The crude male mortality rate (per 100000 ) was 1626.3 in 1995 and 1181.6 in 2016, and the crude female mortality rates were 1296.2 and 1143.3 , respectively. The corresponding age-standardised male mortality rates were 1896.6 and 977.8 , and the female mortality rates were 895.5 and 475.8. Age was missing for 1178 male deaths and for 207 female deaths; for both sexes, $49 \%$ of these deaths were due to external causes, and for $27 \%$ the underlying cause of death was unknown. More than half of the male deaths (102 497) and nearly a quarter of the female deaths (44080) were classified as premature adult deaths (age 20-69 years) in the current study. Of these, external causes accounted for $23.7 \%$ of the male deaths and $12.2 \%$ of the female deaths; the underlying cause of death was unknown for $2.4 \%$ and $1.2 \%$ of premature deaths, respectively.

Over the 22 years of the study, there was a roughly twofold decrease in the overall mortality for both men and women: the ASMR per 100000 dropped from 1651.5 to 716.3 and from 530.0 to 255.2 , respectively. Mortality in men exceeded that in women by a factor of three, and the relative sex difference remained stable over the study period (table 1, online supplementary figure S1). All major groups of causes of death, except digestive diseases, demonstrated a steady downward trend for both sexes; a male disadvantage was obvious for all groups of causes of death (figure 2).

Deaths from circulatory diseases formed the largest group, accounting for $36.4 \%$ and $35.8 \%$ of the cases among men and women, respectively. Circulatory disease mortality in men was three times that in women (table 1 , online supplementary figure S1). Female mortality declined faster than male mortality; for men, the decline accelerated from 2007 onwards (AAPC -6.0) (online supplementary table S1). Sex inequalities widened significantly over time. A particularly rapid decrease was observed in mortality from ischaemic heart disease and cerebrovascular disease (table 1). Substantial sex disparities in mortality from ischaemic heart disease were found in the younger age group (MRR 6.54) (online supplementary table S2).

The risk of death from neoplasms among men was nearly twice that among women; however, the decline was slightly faster for men. Extremely high MRRs were observed for UADT and lung cancer (10.26 and 7.00, respectively). While male mortality from these cancers decreased significantly, female mortality remained unchanged for UADT cancer and increased for lung cancer. Thus, sex differences have diminished significantly over time. The MRRs in the older age group were approximately twice those in the younger age group for UADT cancer ( 10.40 and 5.75 , respectively) and for lung cancer (7.12 and 3.00, respectively).

A fivefold male disadvantage in respiratory disease mortality persisted throughout the study period. An especially high, but somewhat decreasing MRR was found for COPD; mortality decreased faster among men (table 1, figure 3); also here, the MMR was twice as high in the older age group compared with the younger age group (6.61 vs 3.09).

The MRR for digestive diseases remained near 2.5 with no significant change over time. The liver cirrhosis mortality curve followed the shape of the digestive disease mortality curve (figures 2 and 3), increasing during the first subperiod and fluctuating afterwards; mortality in men exceeded that in women more than twice (no differences between the younger and older age groups) and sex inequalities grew slightly over time (table 1, online supplementary tables S1 and S2).

There was a stable over fivefold higher male mortality from external causes. Mortality in both sexes dropped almost at the same pace; the decrease in men was more rapid in the later subperiod (AAPC -7.3). Poisoning by narcotics was the only cause manifesting a rapid increase with a decreasing sex gap. All selected external causes showed larger sex disparities in the younger than in the older age group; the highest MRRs were detected for suicide (6.98 in the younger and 5.59 in the older age group).

Mortality from AP fluctuated in the first subperiod and decreased rapidly from 2007 onwards for both sexes (AAPC -7.4 for men and -8.9 for women) (online supplementary table S1); however, a continuous, fourfold male disadvantage was evident (table 1, online supplementary figure S1); the MRR in the younger age group exceeded that in the older age group (4.63 and 3.82, respectively).

The analysed health behavioural characteristics demonstrated opposite trends (figure 4). Daily smoking prevalence decreased from $47.1 \%$ among men and $21.7 \%$ among women in 1996 to $30.9 \%$ and $15.8 \%$, respectively, in 2016, with the men-to-women PPR of 2.16 (95\% CI 2.05 to 2.27). Heavy episodic drinking prevalence increased from $20.0 \%$ among men and $2.3 \%$ among women in 2000 to $27.3 \%$ and $5.2 \%$, respectively, in 2016; the men-towomen PPR was 6.39 (95\% CI 5.78 to 7.06). Hazardous drinking prevalence in men rose from $8.0 \%$ in 1996 to its maximum of $18.6 \%$ in 2008, then reversed and reached $15.6 \%$ in 2016; among women, the prevalence was $1.1 \%$ in 1996 and $2.9 \%$ in 2016. The men-to-women PPR was 5.84 (95\% CI 5.19 to 6.57$)$.

\section{DISCUSSION}

Premature mortality in Estonia has decreased considerably in 1995-2016. However, this positive development has not reduced the extremely large relative sex disparities as male and female mortality kept declining at the same pace. Large-scale health system reforms performed after regaining Estonian independence, including the utilisation of new medical technologies, better healthcare and a solidarity-based health insurance system, markedly contributed to the downturn in mortality. ${ }^{52}$ There is no reason to believe that access to and quality of healthcare 


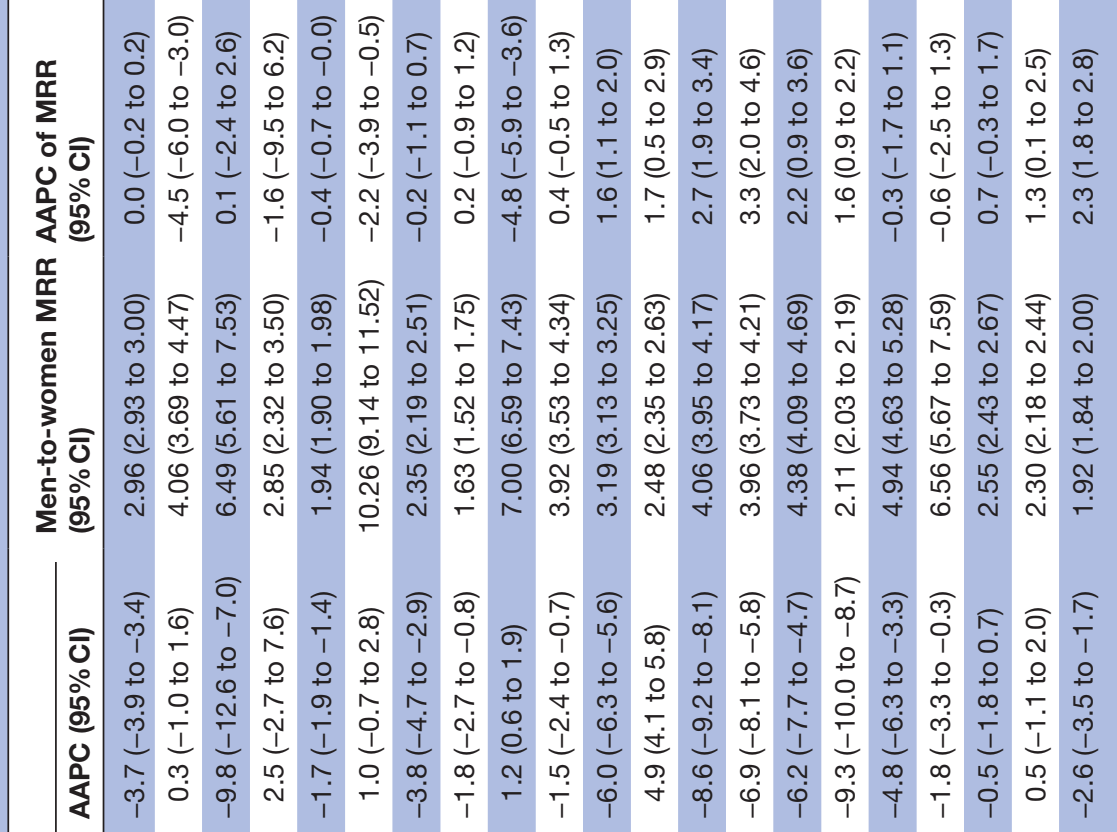

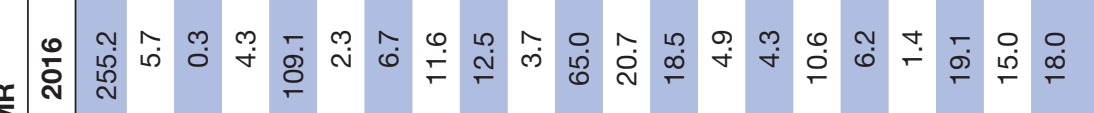

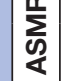

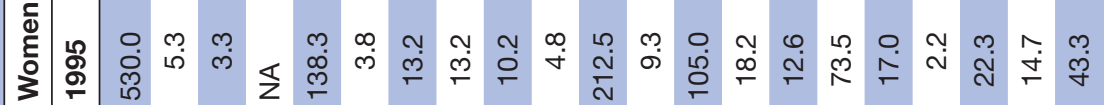
ব का

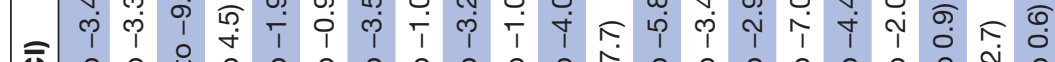

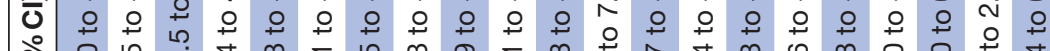

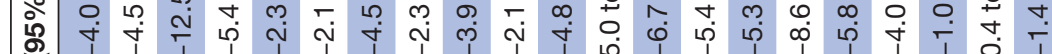

$\stackrel{0}{\circ}$ - I I I I I I I I I I b 1 I I I I I I

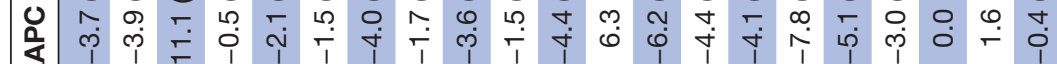

เి

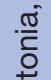
剀

○ ๓ 商 ก) $\sigma \stackrel{\text { ஸे }}{\stackrel{\infty}{\sim}} \stackrel{\infty}{\stackrel{\infty}{\sim}}$ $\sum_{\text {S }}$ क्ष

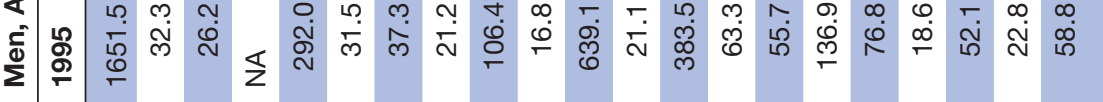
$-\frac{0}{1}$

ळิ $\widehat{m} \widehat{\infty} \widehat{\Phi}$ 送 요요 요 (1) กิ $\partial$ 市 유요 웅 i

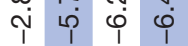

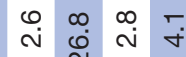
$\infty m \infty$

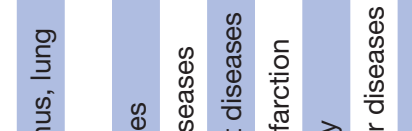

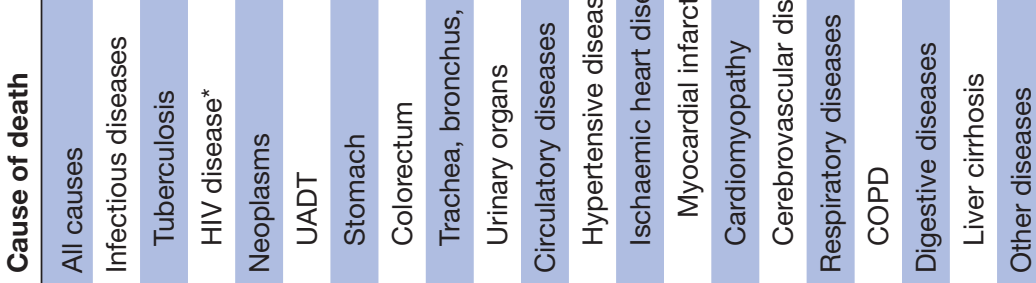

ํㅏㅇ ว एक ㅇㅇㅇㅇ m T 1 0 ए

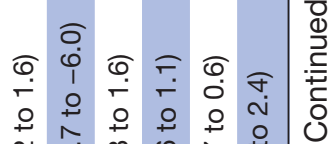
กิ 1 I I I I 人ิं

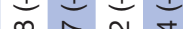

๓ 우 மึ ले लं

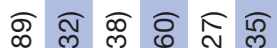
+ $\infty$ 守 웅ㅇㅇㅇㅇㅇ ठ च ம 吕

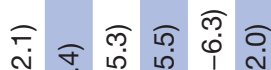
$\begin{array}{llllll}0 & 0 & 0 & 0 & 0 & 2\end{array}$ $\infty$ 우

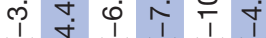
บ ก

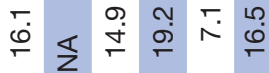

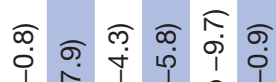

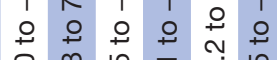
० $m$ n ம) a m a d 宁

○.

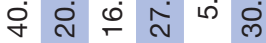

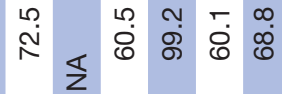

ถึ่

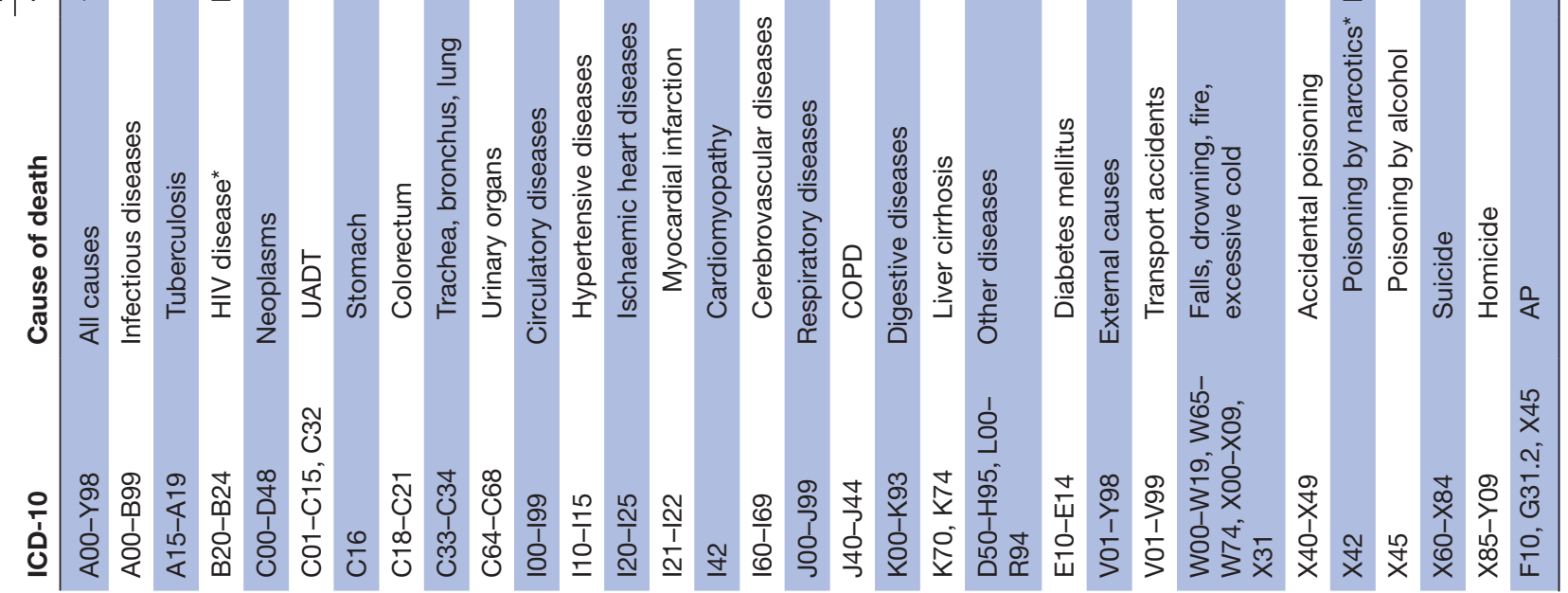

7
0
0
$=0$
0
0
0
0
0
0
0
0
0
0
0
0
0
0
0
0
0
0
0
0
8
0
0
0
1 
varies between men and women; likewise, methods of assigning cause of death do not differ markedly between sexes. Although there exist sex differences in utilisation of healthcare services in Estonia, ${ }^{25}$ their effect on the sex gap in mortality is presumably small. Thus, in interpreting sex disparities in mortality, we should focus on behavioural risk factors. Here, we have addressed tobacco smoking and alcohol consumption as well-known strong mortality risk factors, ${ }^{17-20} 2627$ which contribute to the sex gap in mortality through the different prevalence among men and women. ${ }^{28}$ Both exposures are potentially controllable in the population by effective public health policy. We did not consider other behavioural risk factors for mortality, for example, excess weight or physical inactivity, because their prevalence has not notably differed among men and women in Estonia. ${ }^{15}$ In the low-income and middle-income countries of Europe, the population attributable risk of overweight and obesity for mortality was estimated to be approximately half of that of smoking and alcohol combined. ${ }^{29}$ By a conservative estimate, based on 2003-2005 data, smoking-related and alcohol-related deaths accounted for $71 \%$ of the mortality sex gap in Estonia. ${ }^{30}$ Consequently, a clear dominance of two major adverse health behaviours in Estonia leaves little space for the possibility that other health determinants can be significant contributors to this gap in premature mortality.

\section{Tobacco}

Tobacco smoking is known to be the major avoidable risk factor for cancer, circulatory and respiratory diseases, ${ }^{172627}$ which are the leading groups of non-external causes of death. As smoking is the dominant cause of lung cancer, mortality from it follows the trend of smoking prevalence in the population with a lag time of some decades. ${ }^{31-33} \mathrm{In}$ our study, the lung cancer mortality decreased substantially in men and increased slightly in women, indicating sex dissimilarities in the trend of smoking prevalence in the past. In men, the lung cancer mortality trend was consistent with the COPD mortality trend, which is also known to reflect changes in smoking behaviour. ${ }^{21}$ The COPD mortality in women fluctuated due to the small number of cases. Both, the lung cancer and COPD men-to-women MRRs pointed to a much higher smoking prevalence among men.

According to the Finbalt survey, self-reported daily smoking prevalence showed a steady decrease since 2004 for both sexes, but the prevalence in men was twice that of women; however, the smoking prevalence among men has declined faster than that among women. In Europe, men-to-women smoking PPRs above 1.5 have been mainly seen in postcommunist countries where women have traditionally smoked far less. ${ }^{34}$ Premature mortality among smokers is estimated to be 2-3 times that among never smokers, which means an average of 10 years shorter life expectancy if they do not quit smoking. ${ }^{35}$ If (by an optimistic scenario) smoking prevalence in Estonia keeps the current trend, a continuing decrease in premature 

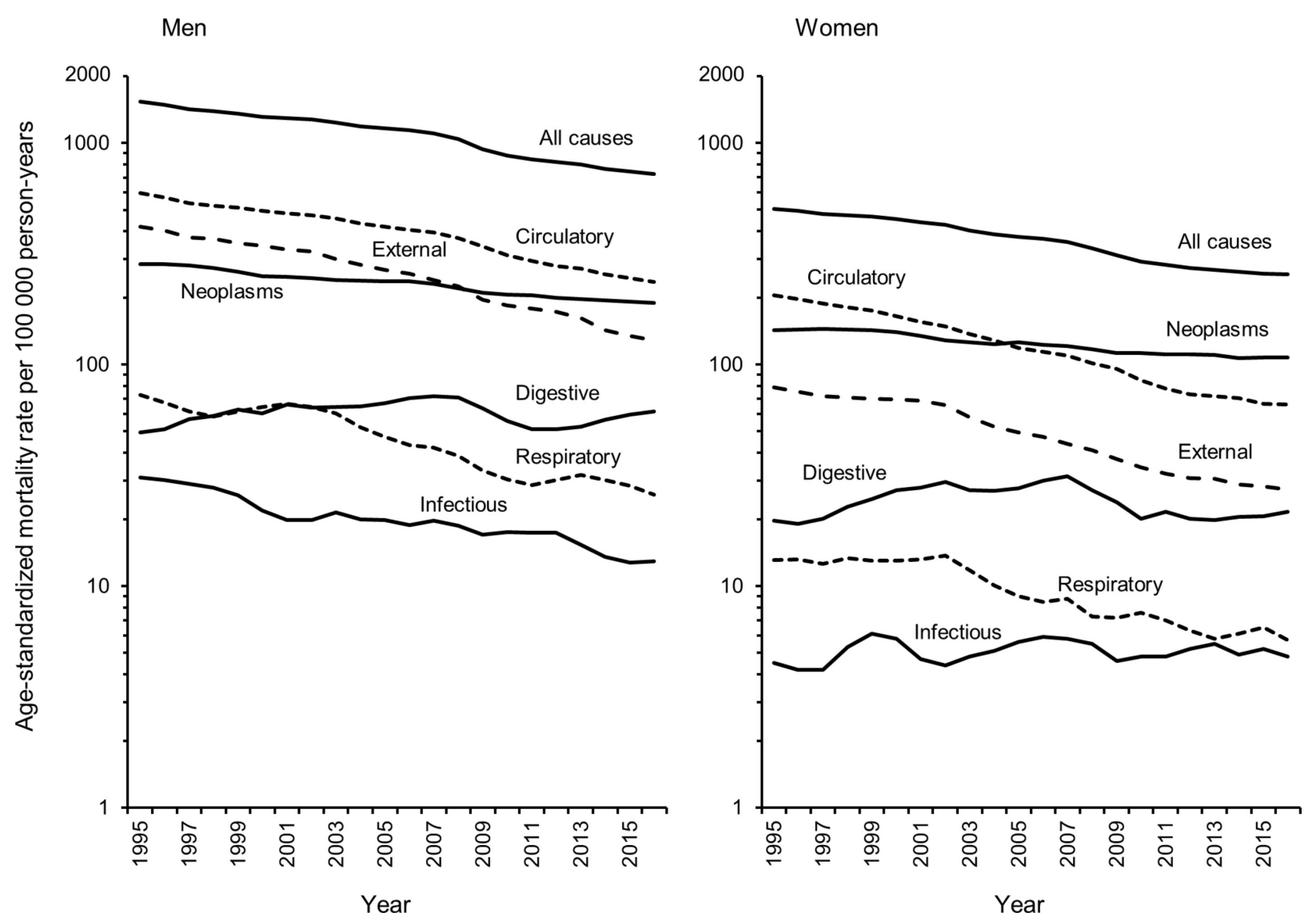

Figure 2 Three-year moving age-standardised mortality rates (European standard population) by major groups of death causes, age 20-69 years, Estonia, 1995-2016.

mortality rates and narrowing of the sex gap would be expected.

\section{Alcohol}

Another strong behavioural risk factor for mortality, alcohol consumption, is related to cancer, digestive diseases and mental disorders, and there is no safe amount of alcohol for these diseases. ${ }^{18-20}{ }^{36}$ Alcohol is closely linked to accidents, suicide and homicide ${ }^{193637}$ Different studies have led to controversial conclusions about a potential cardioprotective effect of light to moderate alcohol drinking ${ }^{38}$; however, accumulating evidence suggests that there is no beneficial effect of alcohol intake on circulatory diseases. ${ }^{19} 3940$ Heavy drinking has been convincingly found to be detrimental to cardiovascular health. ${ }^{27} 4142$ Numerous studies have demonstrated that the high premature mortality among men in the European countries of the former Soviet Union (including Estonia) has been driven by circulatory diseases and has reflected the volume and pattern of alcohol consumption. ${ }^{53-46}$

Estonia is recognised as a spirits/beer-drinking country, where alcohol is consumed irregularly with binge drinking occasions on weekends and where drunkenness among men is socially acceptable. ${ }^{22}{ }^{47}$ Pure alcohol consumption per capita at age $\geq 15$ years was $10.2 \mathrm{~L}$ in 2016 and it has diminished by $1.7 \mathrm{~L}$ since 2009 . These estimates increased from 1995 and peaked at $14.8 \mathrm{~L}$ in $2007 .^{22} 48$
In our study, the decline in circulatory disease mortality was significantly faster among women resulting in an increasing sex gap. Of all the main groups of circulatory diseases, elevated mortality has been found only for hypertensive disease. At the same time, an impressive decrease in cerebrovascular disease mortality was apparent. Partly explained by mutual erroneous coding, ${ }^{49}$ this practice had a similar impact on male and female mortality. Harmful drinking is likely responsible for the increasing sex gap in circulatory disease mortality rather than smoking, as there has been a faster decline in smoking prevalence among men. However, we should keep in mind the effect of largely improved healthcare on the steady decline in circulatory disease mortality.

The level of liver cirrhosis mortality is often used as an indicator of the volume of drinking in the population as average volume of alcohol consumption is associated with liver cirrhosis mortality in a dose-response manner; the link is estimated to be stronger in spirits-drinking countries. ${ }^{19} 2050$ Thus, by estimation, in spirits-drinking countries, a $1 \mathrm{~L}$ increase in alcohol consumption per capita entails a $3.5 \%$ increase in liver cirrhosis mortality in the same year. ${ }^{51}$ Premature liver cirrhosis mortality rates in Estonia grew sharply up to 2007-2008, which coincided with the highest level of per capita alcohol consumption. The men-to-women liver cirrhosis MRR indicated that men in Estonia used to drink much more 


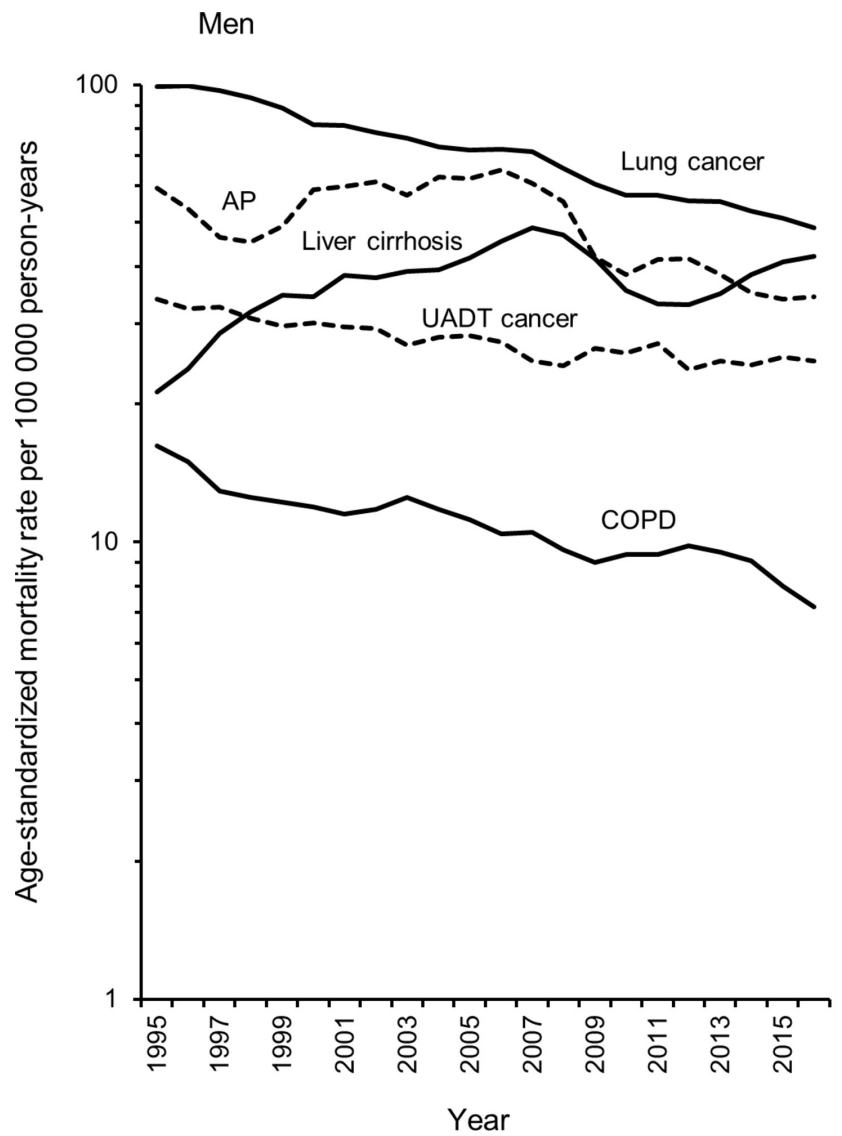

Women

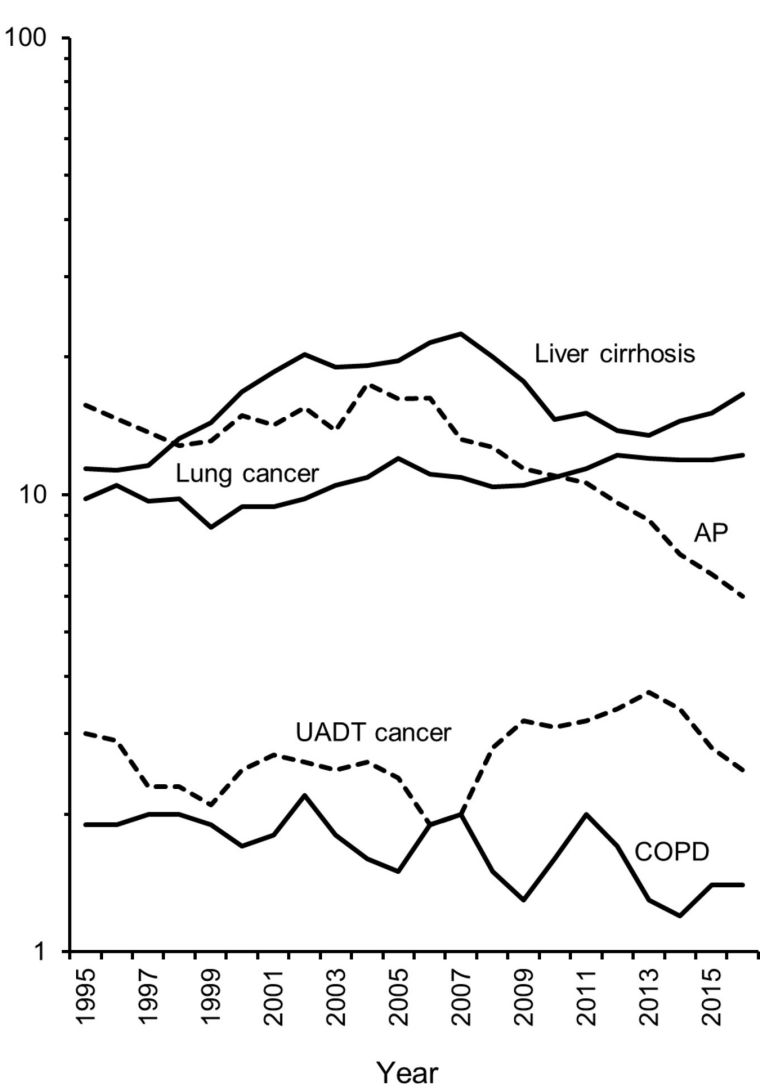

Figure 3 Three-year moving age-standardised mortality rates (European standard population) by selected tobacco-induced and/or alcohol-induced death causes, age 20-69 years, Estonia, 1995-2016. AP, alcohol poisoning, mental disorders due to alcohol and alcohol-related degeneration of the nervous system as a group; COPD, chronic obstructive pulmonary disease; UADT, upper aerodigestive tract.

than women, and this difference has increased in recent years. Although Estonia is known for high liver disease mortality, ${ }^{20}$ these mortality rates could have been even somewhat higher because in the causes of death register, alcoholic liver disease has sometimes been erroneously coded as alcoholism. ${ }^{9}$

Drinking culture characterised by a large volume of alcohol use with binge drinking episodes is responsible for the elevated mortality due to alcohol poisoning in the population. ${ }^{41952}$ In the current study, we used a joint category of AP mortality instead of alcohol poisoning alone because of long-term death certificate coding practices (at least since 2000) in Estonia that have led to an undercoding of alcohol poisoning and overcoding of alcoholism. ${ }^{9}$ AP mortality increased slightly among men up to 2007 (the peak of alcohol consumption in the population) and fluctuated without a noticeable trend among women; the following decrease was rapid, especially among women. The men-to-women MRR for AP demonstrated a more hazardous drinking pattern among men.

Because there is a strong association between alcohol consumption and mortality from external causes, these mortality rates should have mirrored alcohol-induced (liver disease and AP) mortality. However, we did not observe a similar trend during the first half of the study period. While there was an upward trend in alcohol-induced mortality in 1995-2007, mortality from external causes dropped for both sexes throughout the study period. The decline was faster since 2007 and was consistent with the reduced alcohol-induced mortality. Male disadvantage was obvious and did not decrease for any of the single external causes that could be related to alcohol. The opposite trends for external causes and for alcohol-induced causes of death up to 2007 cannot be explained by a weak effect of alcohol but was presumably the result of improved safety and major innovations in healthcare after the change in political regime that could save more lives than alcohol could kill.

Although heavy alcohol consumption is underestimated in self-reports, ${ }^{53}$ the Finbalt survey data have supported the findings from the analysis of premature mortality, indicating that drinking habits of men were far more detrimental than those of women. Heavy episodic drinking and hazardous drinking prevalence among men exceeded that of women about six times. Both characteristics had an increasing prevalence trend among women; among men, while heavy episodic drinking prevalence continued to grow, hazardous drinking prevalence trend reversed in 2008, corresponding to the economic recession. 
Men

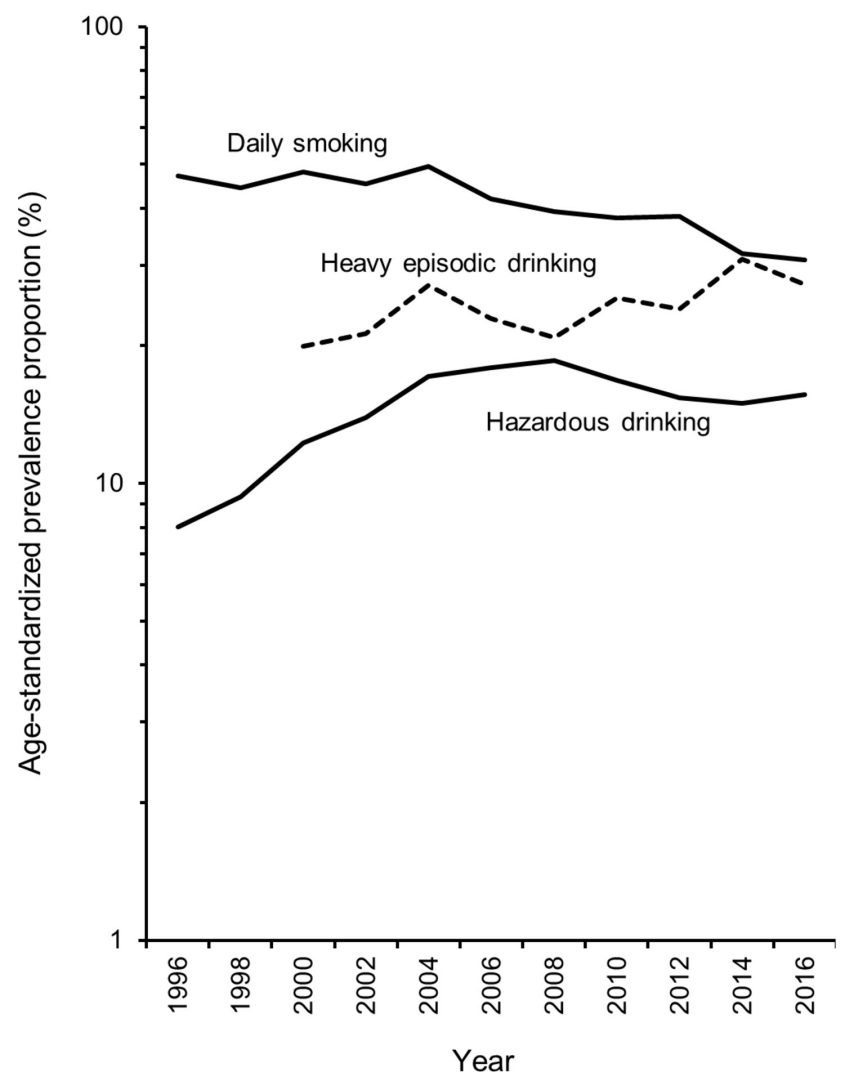

Women

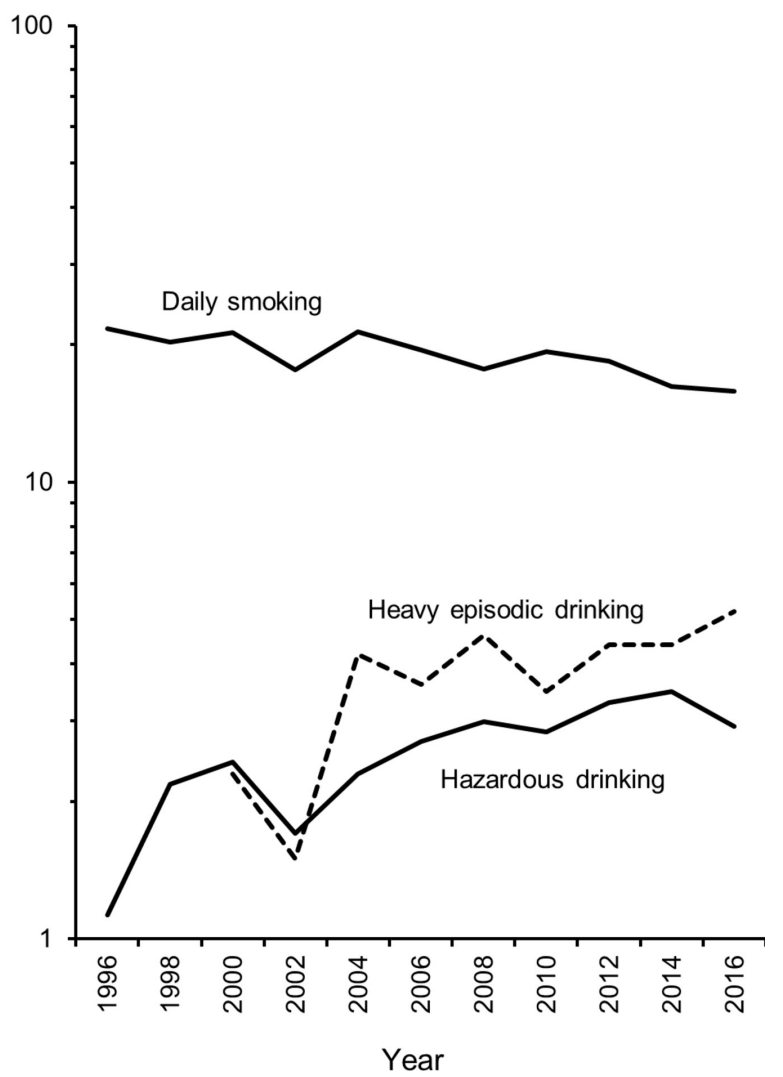

Figure 4 Age-standardised prevalence proportions (European standard population) for daily smoking, heavy episodic drinking and hazardous drinking, age 20-64 years, Estonia, 1996-2016.

\section{Tobacco and alcohol combined}

Two major groups of causes of death-cancer and circulatory diseases-share two main behavioural risk factors: smoking and alcohol consumption. Not surprisingly, premature mortality from these causes among men was many times higher than that among women because men's smoking and drinking habits are much more detrimental. The joint effect of tobacco and alcohol can be observed in UADT cancer mortality rates as an indicator of heavy smoking in combination with heavy drinking. ${ }^{17} 1854$ The marked 10-fold male disadvantage in UADT cancer mortality reveals the essence of the extremely high male premature mortality in Estonia. A strong link of alcohol and tobacco with premature mortality was evident from a study of 169 autopsies in Estonia (male deaths, aged 25-54 years), where alcohol was found in the blood in $95 \%$ of cases and proxy informants reported current smoking among $78 \%$ of them. ${ }^{55}$

\section{Tobacco and alcohol policy}

The decreasing smoking prevalence indicates that the tobacco control policy in Estonia can be considered a success: inflation-adjusted tobacco prices have grown steadily, advertising of tobacco products is banned, smoking in public places is restricted, and smoking cessation service is a part of the healthcare system. ${ }^{567}$ Because there has been no cigarette industry in Estonia since 1996 and no producers lobby to resist regulations, it has been easier to implement tobacco control programmes. However, tobacco is still readily available, with 3.9 sales points per 1000 people in $2015 .^{57}$

In contrast to tobacco policy, alcohol control measures in Estonia have been weak. ${ }^{48}$ Summarised by WHO, the key interventions to handle the adverse effects of alcohol include a pricing policy, restricting advertising and limiting availability. In addition, drink-driving, brief counselling and treatment for alcohol dependence should be addressed. ${ }^{58}$

The excise tax for the most consumed beverages (strong alcohol and beer) was raised by $10 \%$ and $20 \%$ (twice) in 2008 , then by $10 \%$ in 2010 , by $5 \%$ each year in $2012-2014$, and by $15 \%$ in 2015 and 2016 (by the Excise Tax Act). The economic recession in combination with an increase in alcohol prices contributed to a marked reduction in alcohol consumption in 2008-2009. ${ }^{48}$ However, subsequent growth of average income has nullified the effect of higher taxes, and alcohol prices have remained relatively low. ${ }^{22}$ Thus, for example, the price of a $0.5 \mathrm{~L}$ vodka bottle with $40 \%$ alcohol content is equal to the price of two cups of coffee. A minimum unit price policy as a potentially successful measure in reducing heavy drinking ${ }^{59} 60$ has not been considered in Estonia so far.

The Estonian government has made some efforts to control the availability and advertisements of alcohol: retail sale of alcohol is only permitted from 10:00 to 22:00 hours with no exceptions on weekends; the age 
limit for buying or consuming alcohol is 18 years; selling alcohol to persons with signs of intoxication is prohibited; and the Advertising Act regulates alcohol advertising. No limitations exist for the number of alcohol sales pointsin 2016, there were 5.6 sales points per 1000 people. ${ }^{22}$ Thus, changes have been minor, and alcohol still has remained extremely affordable and available in Estonia.

The only effective antialcohol measure so far has been strict control of drunk driving. The legal blood alcohol concentration is $0.02 \%$ in Estonia while driving, and random breath testing is implemented. A rapid decrease in mortality due to transport accidents attests to the benefits of these measures.

Brief screening and counselling for alcohol misuse are limited in primary healthcare because these programmes are not incorporated into the services list of the health insurance fund and, therefore, rely on project funding from the European Social Fund and the good will of family doctors. Treatment for alcohol dependence is an expensive out-of-pocket service, and only therapy for acute conditions is financed by the health insurance fund.

A short overview of alcohol-related harm and evidencebased recommendations to reduce it were published in the 'Green Paper on Alcohol Policy' issued by the Ministry of Social Affairs. ${ }^{61}$ However, there are still no successful legislation initiatives to implement these guidelines. Although the seriousness of the problems associated with alcohol is admitted by the public, ${ }^{22}$ the draft act on alcohol restrictions met fierce resistance from alcohol producers and was not accepted by the government. Like elsewhere, the country's efforts have faced commercial interests of the alcohol industry to block responsible legislation. ${ }^{62} 63$

\section{Limitations}

The results of this study rely on the data quality of the Estonian causes of death register. Although in international comparisons the death data were considered to be of high quality with respect to timeliness, coverage, completeness, the used ICD revision and the proportion of unknown causes, ${ }^{64}$ we are aware of some systematic misclassifications $^{9}{ }^{49}$ that may bias the cause-specific mortality rates. Because of undercoding of alcohol poisoning, mortality rates for the broad category of external causes were also somewhat underestimated.

We excluded deaths with unknown age at death from the analyses; half of these were from external causes. It is likely that the majority of those would have belonged to the age group of 20-69 years. This exclusion reduced the mortality rates. As we excluded relatively more male deaths, the MRRs could be slightly reduced. In addition, deaths at the age of 20-69 years with unknown cause were more common among men. If we had known these causes, other cause-specific mortality rates would have been somewhat higher, especially in men. Thus, the unknown category additionally reduced the cause-specific MRRs.

Because the latency period between an initial exposure to tobacco and alcohol, and the onset of disease can be several decades, the patterns of premature mortality due to non-external causes of death reported here, reflect past exposure situations. It is assumed that the prevalence of adverse health behaviours and their contrasts by sex were in the past in the same order of magnitude as in some last decades.

\section{CONCLUSIONS}

Even though premature adult mortality has markedly decreased over time in Estonia, there has been no success in diminishing the large sex differences in the mortality patterns, many of which were related to smoking and excessive drinking of alcohol, both more prevalent among men. The country's population needs the implementation of a comprehensive and consistent alcohol policy while maintaining and further developing antitobacco measures.

Acknowledgements The authors thank the database manager Tatjana Veideman for providing us with health behaviour survey data.

Contributors $\mathrm{HZ}, \mathrm{KR}$ and MR designed the study. KR analysed the data. $\mathrm{HZ}, \mathrm{KR}$ and MR contributed to the interpretation of findings. KR drafted the manuscript. All authors revised the manuscript critically and approved the final version of the manuscript.

Funding The authors had no specific funding for this work. KR and MR were salaried by their home institute (grant IUT5-1 from the Estonian Research Council). The manuscript was refined during a guest research period (KR and MR) at the Leibniz Institute for Prevention Research and Epidemiology-BIPS.

Competing interests None declared.

Patient consent for publication Not required.

Provenance and peer review Not commissioned; externally peer reviewed.

Data sharing statement Mortality data and health behaviour survey data are available at the National Institute for Health Development (http://www.tai.ee/en/).

Open access This is an open access article distributed in accordance with the Creative Commons Attribution Non Commercial (CC BY-NC 4.0) license, which permits others to distribute, remix, adapt, build upon this work non-commercially, and license their derivative works on different terms, provided the original work is properly cited, appropriate credit is given, any changes made indicated, and the use is non-commercial. See: http://creativecommons.org/licenses/by-nc/4.0/.

\section{REFERENCES}

1. United Nations Development Programme. Human development reports. http://hdr.undp.org/en/content/human-development-indexhdi (accessed 18 Jan 2019).

2. Kolip P, Lange C. Gender inequality and the gender gap in life expectancy in the European Union. Eur J Public Health 2018;28:869-72.

3. Statistics Estonia. Main demographic indicators. http://pub.stat. ee/px-web.2001/__Databas/Population/01Population_indicators_ and_composition/02Main_demographic_indicators/02Main_. demographic_indicators.asp (accessed 21 Aug 2018).

4. Grigoriev P, Andreev EM. The huge reduction in adult male mortality in Belarus and Russia: is it attributable to anti-alcohol measures? PLoS One 2015;10:e0138021.

5. Jasilionis D, Meslé F, Shkolnikov VM, et al. Recent Life Expectancy Divergence in Baltic Countries. European Journal of Population / Revue européenne de Démographie 2011;27:403-31.

6. Eurostat. Life expectancy at birth, by sex. http://ec.europa.eu/ eurostat/data/database (accessed 21 Aug 2018).

7. Barford A, Dorling D, Davey Smith G, et al. Life expectancy: women now on top everywhere. BMJ 2006;332:808.

8. Luy $M$, Wegner-Siegmundt $C$. The impact of smoking on gender differences in life expectancy: more heterogeneous than often stated. Eur J Public Health 2015;25:706-10.

9. Rahu K, Palo E, Rahu M. Diminishing trend in alcohol poisoning mortality in Estonia: reality or coding peculiarity? Alcohol Alcohol 2011;46:485-9. 
10. Rahu K, Pärna K, Palo E, et al. Contrasts in alcohol-related mortality in Estonia: education and ethnicity. Alcohol Alcohol 2009;44:517-22.

11. World Health Organization. ICD-9: international statistical classification of diseases and related health problems. 9th revision. Geneva: WHO, 1977.

12. World Health Organization. $I C D-10$ : international statistical classification of diseases and related health problems. 10th revision. Geneva: WHO, 1992.

13. Rahu M, Rahu K, Baburin A. Eesti surmaandmestiku kvaliteedianalüüs. [Quality analysis of the Estonian death data]. Tallinn: NIHD. 2005. [in Estonian] http://rahvatervis.ut.ee/ handle/1/601 (accessed 21 Aug 2018).

14. Soomer $H$, Ranta $H$, Penttilä $A$. Identification of victims from the $M / S$ Estonia. Int J Legal Med 2001;114:259-62.

15. Tekkel M, Veideman T. Health behavior among Estonian adult population, 2016; Tallinn: NIHD. 2017 http://rahvatervis.ut.ee/ bitstream/1/6665/1/Tervisekaitumine2017.pdf (accessed 21 Aug 2018).

16. Waterhouse J, Muir C, Correa P, eds. Cancer Incidence in Five Continents. Vol III. IARC Scientific Publications No. 15. Lyon: IARC, 1976.

17. Leon ME, Peruga A, McNeill A, et al. European code against cancer, 4th edition: tobacco and cancer. Cancer Epidemiol 2015;39:S20-33.

18. Scoccianti C, Cecchini M, Anderson AS, et al. European code against cancer 4th edition: alcohol drinking and cancer. Cancer Epidemiol 2016;45:181-8.

19. Norström T, Ramstedt M. Mortality and population drinking: a review of the literature. Drug Alcohol Rev 2005;24:537-47.

20. Sheron N. Alcohol and liver disease in Europe--Simple measures have the potential to prevent tens of thousands of premature deaths. $J$ Hepatol 2016;64:957-67.

21. Adair T, Hoy D, Dettrick Z, et al. 100 years of mortality due to chronic obstructive pulmonary disease in Australia: the role of tobacco consumption. Int J Tuberc Lung Dis 2012;16:1699-705.

22. Estonian Institute of Economic Research. Alcohol market, consumption and harms in Estonia. Yearbook 2018. Tallinn: EIER, 2018.

23. Devaux M, Sassi F. Alcohol consumption and harmful drinking: Trends and social disparities across OECD countries. OECD Health Working Papers, No. 79. Paris: OECD Publishing, 2015.

24. Lai T, Habicht T, Kahur K, et al. Estonia: health system review. Health Syst Transit 2013;15:1-196.

25. Huijts T, Stornes P, Eikemo TA, et al. The social and behavioural determinants of health in Europe: findings from the European Social Survey (2014) special module on the social determinants of health. Eur J Public Health 2017;27(suppl_1):55-62.

26. Alberg AJ, Shopland DR, Cummings KM. The 2014 Surgeon General's report: commemorating the 50th Anniversary of the 1964 Report of the Advisory Committee to the US Surgeon General and updating the evidence on the health consequences of cigarette smoking. Am J Epidemiol 2014;179:403-12.

27. Ezzati M, Obermeyer Z, Tzoulaki I, et al. Contributions of risk factors and medical care to cardiovascular mortality trends. Nat Rev Cardiol 2015;12:508-30.

28. Rogers RG, Everett BG, Onge JM, et al. Social, behavioral, and biological factors, and sex differences in mortality. Demography 2010;47:555-78.

29. World Health Organization. Global health risks. Mortality and burden of disease attributable to selected major risks. Geneva: WHO Press, 2009.

30. McCartney G, Mahmood L, Leyland AH, et al. Contribution of smoking-related and alcohol-related deaths to the gender gap in mortality: evidence from 30 European countries. Tob Control 2011;20:166-8.

31. Weiss W. Cigarette smoking and lung cancer trends. A light at the end of the tunnel? Chest 1997;111:1414-6.

32. National Research Council. Explaining divergent levels of longevity in high-income countries. Washington: The National Academies Press, 2011:150.

33. Islami F, Torre LA, Jemal A. Global trends of lung cancer mortality and smoking prevalence. Trans/ Lung Cancer Res 2015;4:327-38.

34. Gallus S, Lugo A, La Vecchia C, et al. Pricing Policies And Control of Tobacco in Europe (PPACTE) project: cross-national comparison of smoking prevalence in 18 European countries. Eur J Cancer Prev 2014;23:177-85.

35. Jha P, Peto R. Global effects of smoking, of quitting, and of taxing tobacco. N Engl J Med 2014;370:60-8.

36. Rehm J, Gmel GE, Gmel G, et al. The relationship between different dimensions of alcohol use and the burden of disease-an update. Addiction 2017;112:968-1001.
37. Taylor B, Irving HM, Kanteres F, et al. The more you drink, the harder you fall: a systematic review and meta-analysis of how acute alcohol consumption and injury or collision risk increase together. Drug Alcohol Depend 2010;110:108-16.

38. Ronksley PE, Brien SE, Turner BJ, et al. Association of alcohol consumption with selected cardiovascular disease outcomes: a systematic review and meta-analysis. BMJ 2011;342:d671.

39. Zhao J, Stockwell T, Roemer A, et al. Alcohol consumption and mortality from coronary heart disease: an updated meta-analysis of cohort studies. J Stud Alcohol Drugs 2017;78:375-86.

40. Holmes MV, Dale CE, Zuccolo L, et al. Association between alcohol and cardiovascular disease: Mendelian randomisation analysis based on individual participant data. BMJ 2014;349:g4164.

41. Leon DA, Shkolnikov VM, McKee M, et al. Alcohol increases circulatory disease mortality in Russia: acute and chronic effects or misattribution of cause? Int J Epidemiol 2010;39:1279-90.

42. Rehm J, Roerecke M. Cardiovascular effects of alcohol consumption. Trends Cardiovasc Med 2017;27:534-8.

43. McKee M, Shkolnikov V. Understanding the toll of premature death among men in eastern Europe. BMJ 2001;323:1051-5.

44. Leon DA, Shkolnikov VM, McKee M. Alcohol and Russian mortality: a continuing crisis. Addiction 2009;104:1630-6.

45. Karanikolos M, Leon DA, Smith PC, et al. Minding the gap: changes in life expectancy in the Baltic States compared with Finland. $J$ Epidemiol Community Health 2012;66:1043-9.

46. Zaridze D, Lewington S, Boroda A, et al. Alcohol and mortality in Russia: prospective observational study of 151,000 adults. Lancet 2014;383:1465-73.

47. Popova S, Rehm J, Patra J, et al. Comparing alcohol consumption in central and eastern Europe to other European countries. Alcohol Alcohol 2007;42:465-73

48. Lai T, Habicht J. Decline in alcohol consumption in Estonia: combined effects of strengthened alcohol policy and economic downturn. Alcohol Alcohol 2011:46:200-3.

49. Denissov G. Sharp decrease in observed cerebrovascular mortality may be due to certification and coding. Scand J Public Health 2016;44:335-7.

50. Rehm J, Taylor B, Mohapatra S, et al. Alcohol as a risk factor for liver cirrhosis: a systematic review and meta-analysis. Drug Alcohol Rev 2010;29:437-45.

51. Ramstedt M. Population drinking and liver cirrhosis mortality: is there a link in eastern Europe? Addiction 2007;102:1212-23.

52. Stickley A, Leinsalu M, Andreev E, et al. Alcohol poisoning in Russia and the countries in the European part of the former Soviet Union, 1970 2002. Eur J Public Health 2007;17:444-9.

53. Gual A, Ángel Arbesú J, Zarco J, et al. Risky drinkers underestimate their own alcohol consumption. Alcohol Alcohol 2017;52:516-7.

54. Anantharaman D, Marron M, Lagiou P, et al. Population attributable risk of tobacco and alcohol for upper aerodigestive tract cancer. Oral Oncol 2011;47:725-31.

55. Ringmets I, Tuusov J, Lang K, et al. Alcohol and premature death in Estonian men: a study of forensic autopsies using novel biomarkers and proxy informants. BMC Public Health 2012;12:146.

56. Lai T, Habicht J, Reinap M, et al. Costs, health effects and costeffectiveness of alcohol and tobacco control strategies in Estonia. Health Policy 2007;84:75-88.

57. Estonian Institute of Economic Research. Tobacco market and consumption in Estonia. Yearbook 2015. Tallinn: EIER, 2015.

58. World Health Organization. Global status report on alcohol and health. Geneva: WHO Press, 2014.

59. Burton $\mathrm{R}$, Henn $\mathrm{C}$, Lavoie $\mathrm{D}$, et al. A rapid evidence review of the effectiveness and cost-effectiveness of alcohol control policies: an English perspective. Lancet 2017;389:1558-80.

60. Boniface S, Scannell JW, Marlow S. Evidence for the effectiveness of minimum pricing of alcohol: a systematic review and assessment using the Bradford Hill criteria for causality. BMJ Open 2017;7:e013497.

61. Ministry of Social Affairs. Green Paper on alcohol policy. Tallinn: Ministry of Social Affairs. 2014 https://www.sm.ee/sites/default/files/ content-editors/eesmargid_ja_tegevused/Tervis/Tervislik_eluviis/ alkoholi_roheline_raamat-19.02.14_12_en.pdf (accessed 21 Aug 2018).

62. McCambridge J, Mialon M, Hawkins B. Alcohol industry involvement in policymaking: a systematic review. Addiction 2018;113:1571-84.

63. Casswell $\mathrm{S}$, Callinan $\mathrm{S}$, Chaiyasong $\mathrm{S}$, et al. How the alcohol industry relies on harmful use of alcohol and works to protect its profits. Drug Alcohol Rev 2016;35:661-4.

64. Mahapatra P, Shibuya K, Lopez AD, et al. Civil registration systems and vital statistics: successes and missed opportunities. Lancet 2007;370:1653-63. 